\title{
REMEMBER GERHARD RICHTER IN THE THUNDERSTORM OF BEETHOVEN: THE INFLUENCE OF CROSS-SENSORY COUPLING ON MEMORY, INTERCULTURAL COMMUNICATION, AND THE VERBALIZATION OF PAINTINGS AND SOUNDS
}

\author{
EMILIE MARTINEZ \\ Friedrich Schiller University, Jena, Germany \\ Emilie.Martinez@uni-jena.de
}

\begin{abstract}
This interdisciplinary study focuses on the perception and verbalization of messages conveyed through instrumental music, soundscapes, and contemporary paintings. International young-adult university students learning German participated in a series of experiments conducted at Friedrich Schiller University in Jena, Germany. To incorporate globalization and cultural difference into this analysis, the author compared the reactions of Western and Asian participants to auditory and visual stimuli. This paper explores the concepts of mixed media, cross-sensory coupling, and esthetic synesthesia, and throws new light on the contribution of cross-sensory coupling to verbalization and to long-term memory processes, from encoding to retrieval. In addition, the author demonstrates how intercultural communication is based upon universal emotions aroused by contemporary paintings, instrumental music and soundscapes.
\end{abstract}

\section{Introduction}

\subsection{From cross-sensory coupling to aesthetic synesthesia: Focus on specific terms}

Cross-sensory coupling (i.e., the coupling of various senses) is a process that each individual experiences. This process may take place purposefully, for instance, when sounds are associated with images by movie makers; it may occur on a less conscious level, e.g., when a piece of classical music such as Beethoven's Ninth Symphony arouses personal memories in the form of mental images in rapt listeners. Indeed, there is a universal tendency towards coupling visual and auditory stimuli. Haverkamp (2003) shows evidence that this tendency is genetically hardwired into each of us. In my opinion, this tendency may thus be referred to as a human need. Given this evidence as to the deep roots of cross-sensory coupling, it is no coincidence that modern societies feature the coupling of auditory and visual stimuli through movies and advertisements, indeed, through almost the entire art-making world. 
This paper focuses on a type of cross-sensory coupling which may, at first glance, appear less natural than the two aforementioned types: the coupling of contemporary paintings to instrumental music and soundscapes - two types of mixed media. Mixed media (Higgins 2000 as cited in Heibach 2004: 164) involves two or more different mediums, which are combined without losing their original form. Mixed media differs from forms of cross-sensory coupling that are predicated on the fusion of two mediums: television, for instance, involves the fusion of sounds and images. The combination of paintings with music pieces or soundscapes is referred to as aesthetic synesthesia (Heibach 2004), as opposed to medical synesthesia, a different phenomenon.

\subsection{Research focus and goals of this paper}

The very term aesthetic synesthesia implies that aesthetics plays a key role. However, art, as "an object of aesthetic feelings, a source of knowledge about societies and their cultures and an inducer of emotional reactions among people [...] can achieve its educational aim only when it is properly and carefully perceived, experienced and comprehended" (Krawiec 2012: 90-91) by its recipients. As Martinez (2013) points out, "[j]udging a painting based mainly on its beauty is not the main task today's art educators assign to spectators." Beyond making an aesthetic judgment, recipients are expected to be capable of finding out the (metaphorical) meaning of a piece of art -in other words, to interpret it. Even though "[s]eeing comes before words and can never be quite covered by them" (Berger 1977 as cited in Blell 2006: 6), the main task I assigned the participants of the studies I conducted in 2011 and 2012 was to verbalize the messages and feelings conveyed by visual and auditory works of art. Lay audiences tend to encounter striking difficulties when asked to put messages conveyed by contemporary paintings into words. While Badstübner-Kizik (2004: 10) stresses this incapacity, Körner (2008: 120) argues that Western art education has failed for decades; the use of mixed media aims to facilitate the verbalization processes through increasing the arousal of emotions (see Chapter 2 of the present paper). Participants were tasked with giving meaning to what they saw (a wide range of contemporary paintings) and heard (various instrumental music pieces and soundscapes) using only individual associations such as personal memories.

The study groups were young-adult international students from Friedrich Schiller University of Jena, Germany. It is important to note that most studies on aesthetic synesthesia have taken place in the German as a Foreign Language classroom. The first of the three pedagogic concepts introduced by Lightfoot (2007 as cited in Graz 2012: 85) for art use in the classroom, which is referred to as looking at art (as opposed to the concepts of sharing art and creating art) is a perfect tool to achieve the goals of foreign language learning and teaching, since it is based on students' verbal responses to works of art.

A key issue for me is the importance given to cultural difference and globalization, the latter being expressed through the use of soundscapes, the former being represented by the comparison of two cultures: Western and East Asian (Chinese and Japanese). Understanding cultural differences involves finding cultural similarities; intercultural communication played a major role in a language classroom with a multicultural group 
of students. In addition, participants were tested on their capacities to remember the paintings, music pieces, and soundscapes used in their language classroom, as well as the meaning that they assigned to these examples of mixed media.

This paper presents selected samples of the conducted studies, which throw light on the three following main issues: verbalization of messages, intercultural communication, and memory. The goal of this paper is to discuss the contribution of cross-sensory coupling to verbalization and intercultural communication, as well as to memory, and to compare these findings to the aforementioned literature.

Bearing in mind the research focus and the goals of this paper, it is necessary to provide a theoretical and empirical background to concepts such as emotions, learning, and memory. In the upcoming chapter, the role played by emotions within, around, and between individuals is discussed, and paintings, instrumental music, and soundscapes are presented as international languages capable of arousing emotions. Main study findings are illustrated through examples of participant reactions in later chapters.

\section{Emotions within, around, and between individuals}

\section{1 "I feel, therefore I am"}

Emotions are universal: such a statement is nowadays generally taken for granted. Nevertheless, Western civilization had to wait till 1969 to accept this fact, when the ethnologist Paul Ekman presented his findings at the Conference of the American Anthropological Association. He posited that the following six emotions exist in every culture and that individuals use the same facial expressions when experiencing them: anger, disgust, fear, happiness, sorrow, and surprise. Ekman was no naïve universalist; he recognized the influence of educational background on participants' reactions. Only the origins of theses emotions differ from one person to next, and this is partially due to cultural background. For example, being presented with a food that individuals from a specific culture are not used to eating may provoke an expression of disgust, while those who are familiar with this food may see it as a source of pleasure (Antweiler 2009: 7677). Initially, Ekman was mistrusted by its colleagues, and had to conduct further experiments in order to gain recognition.

In The Feeling of What Happens (1999), the Portuguese neuroscientist António Damásio, deals with emotions and the role they play for the human body and mind. Damásio defines emotions as sources of energy whose influence is present in each individual, with the ability to positively or negatively affect the body as well as the mind (Arnold 2002: 64). Thanks to emotions, people from different cultures are capable of successfully communicating with each other (see Part 3.2 of the present paper). The German translation of Damasio's book into I Feel, Therefore I Am (German title: Ich fühle, also bin ich) is a clear wordplay with and an allusion to Descartes' "cogito ego sum" ("I think, therefore I am"). This famous declaration appeared in Descartes" Discourse on the Method (1637), and can be considered a basis for the development of Western philosophy. Such a title sounds familiar to the average reader since it is more or less a copy of Descartes' words. Such a title probably aims to emphasize the role played 
by feelings with regard to cognitive tasks, since "think" has been substituted with "feel." Damasio argues that behind every single thought or decision there is, in fact, a feeling. As Arnold (2002: 72) notes, "one could say each form of consciousness and thus each form of knowledge starts with a feeling, an idea, a desire" (translated from German). Since words are used to express knowledge, one could go further in this direction and state that behind every word, there is a feeling.

Emotions can be expressed through languages other than verbal ones. The next section of this paper will show that behind (artistic) nonverbal languages are hidden emotions, and that nonverbal languages such as (instrumental) music, paintings, and soundscapes are thus capable of making one laugh, cry, or even feel angry.

\subsection{Arousing emotions through international languages}

Emotions are difficult to measure. Nevertheless, the thrills produced by the human body are the expression and, thus, the evidence of the intense emotions one feels when watching a movie, listening to music, or simply looking at a beautiful painting. As Martinez (2013) notes, the neuropsychologist Goldstein who conducted studies in order to examine various causes of thrills, "found that $96 \%$ of thrills were sparked by a musical passage, $92 \%$ by a scene in movie or book, and $87 \%$ by beauty in nature or art." Everyone has experienced sorrow while listening to a sad piece of music. In addition to musical compositions, paintings can arouse emotions in their recipients, and can be understood as international languages. Impressionistic paintings are often praised by contemporary viewers, who experience positive emotions when viewing such works of art. In contrast, viewers from different cultures might never hang such paintings in their living rooms; they would find them as ugly, or feel depressed when they looked at them. Education through art is therefore a process that involves individual experiences of emotions, in which one's emotional predispositons play a major role (Krawiec 2012: 9192).

Goldstein's aforementioned findings may not be representative of every culture. However, with regard to the present study, Yalin (2007) argues that, at least, Western and Chinese cultures have a lot in common, and that similarities between these cultures should be the subject of more scholarly inquiry. A striking illustration of Yalin's assertion can be found the field of Western classical music. Western classical music is not played and listened to only by Westerners, but also by individuals from other cultures, such as the Chinese. A bit surprising is, however, is that the Chinese as well as the Japanese are almost obsessed with Western classical music-to understand their enthusiasm, one needs to go back to its roots, a few centuries ago (see e.g., Hays 2008/2009 or Hewett 2006). Because of the present engagement of China and Japan in classical music, Oestreich (2010) predicts that "the countries of East Asia will become the great conservators of Western classical music" (Oestreich 2010); Chinese and Japanese interest in Western classical music and the high rates of training in Western orchestral instruments among East Asian children are such important factors that famous classical pieces by composers such as Beethoven and Bach were used in the experiments presented later on in the present paper. 
Studies conducted by Gabrielsson/Juslin (1996: 87) not only confirm the similarities between individuals from various cultures, but also throw light on the universal, genetic basis for individuals to react in the same way to specific musical features. In these experiments, three basic emotions (happiness, sadness and anger) expressed by instrumental music were associated in the same way by most listeners to the same piece of music. These findings were incorporated into the research designs of the experiments presented later on in the present paper.

Finally, it needs to be emphasized that not only paintings and music can arouse emotions, but also soundscapes. As Werner (2006: 13) notes, sounds "carry messages, everyday associations and feelings; the listener is composer of his environment which he understands as a language without being aware of it" (translated from the German). A wailing police siren symbolizes danger in most cultures and may therefore arouse fear; birds singing in the spring tends to remind listeners of love and of positive events such as birth. The sounds of other natural elements such as water have the most various meanings, from happiness (stream/creek) and relaxation (ocean waves) to anger (thunderstorm; for a detailed survey of sound perception see Schafer 1988).

\section{The contribution of cross-sensory coupling to verbalization and intercultural communication}

\subsection{The verbalization of paintings, instrumental music, and soundscapes}

\subsubsection{Study groups}

Two study groups were created (Groups 1 and 2). Group 1 was comprised of 120 university students, half of whom came from Western countries and half of whom came from China and Japan. These students were chosen independently based on expressing interest in painting or music, as well as artistic skills. These participants were studying various subjects at Friedrich Schiller University and at the University of Applied Sciences in Jena. Their task consisted of filling in a questionnaire about a step-by-step interpretation of a painting they looked at, both with (experimental groups) and without (control groups) listening to classical music or soundscapes (Martinez 2013). Group 2 was comprised 10 German as a Foreign Language students from both China and Western countries.

Group 1 participated in only one experiment, in their free time, while Group 2 regularly took part in my experiments, which were incorporated into their Germanlearning curriculum. Unlike Group 1, Group 2 expressed their interpretations of the paintings and sounds not only in written form, but also orally, in and outside the classroom, such as during focused interviews conducted after class. In addition, the participants of Group 1 used their mother tongue to express their reactions, while the participants of Group 2 were asked to communicate in German, a foreign language for 
all of them. In summarizing the main findings, the findings from Group 1 are presented with a stress on larger patterns of cultural difference. Findings for Group 2 are given in terms of individual reactions, due the much smaller number of participants.

\subsubsection{Group 1: An intercultural study}

\subsubsection{Procedure}

Participants from Group 1 observed two paintings of elder trees by the German artist Sighard Gille (Figures 1 and 2). The painting depicting white elders blossoming symbolizes life (here, the life painting) and the painting depicting dark blue elders withering symbolizes death (here, the death painting). Group 1 was made up of several experimental groups, who were given various combinations of paintings and sounds. There were also two control groups who observed the life or death painting without any auditory input. The auditory materials were chosen based on their themes of life and death, supposedly reflecting the emotions expressed by the elder tree paintings. Beethoven's Moonlight Sonata was chosen to express sadness and death, and Bach's Badinerie was chosen to express happiness and life. The soundscapes used followed the same rules: one expressed spring (life) through sounds such as birds singing and water flowing, while the other expressing a negative feeling, possibly death, through thunderstorm sounds.

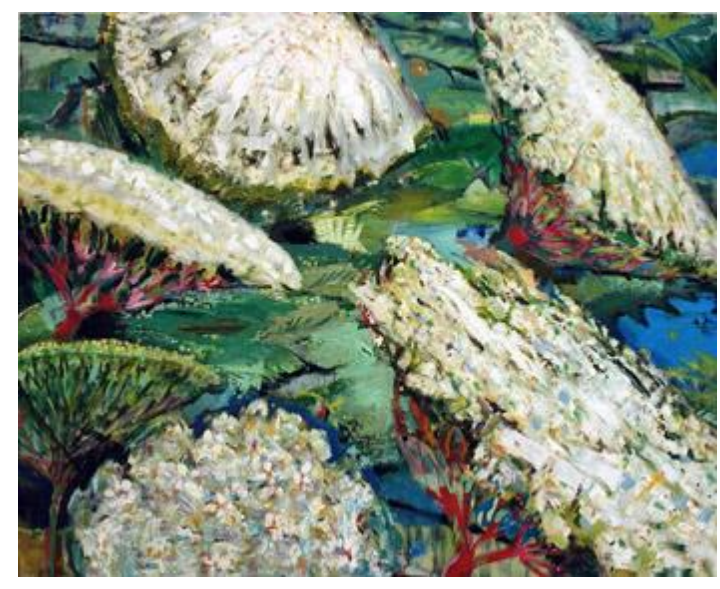

Figure 1: Sambucus, Weißer Holunder. Sighard Gille. 2006. Eitempera, Oil/Canvas. 160 x $120 \mathrm{~cm}$. 


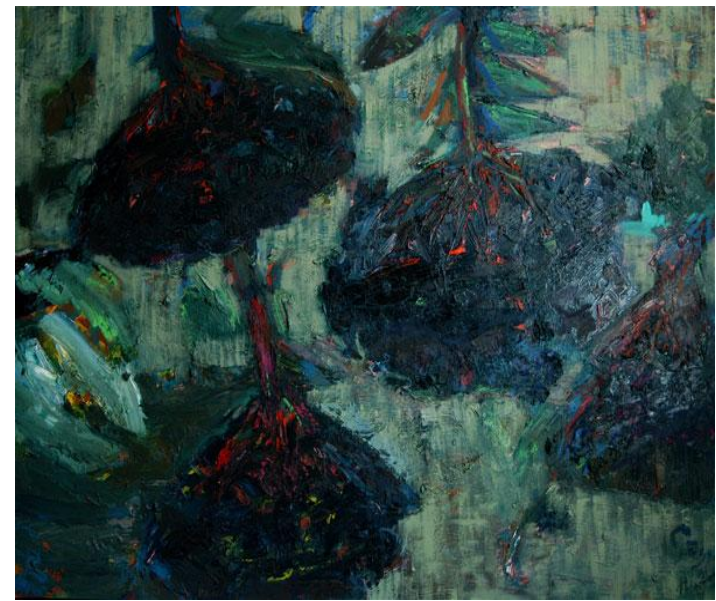

Figure 2: Sambucus, Schwarzer Holunder. Sighard Gille. 2000. Oil/Canvas. 160 x $200 \mathrm{~cm}$.

\subsubsection{Results}

Participants from China were skillful at interpreting both paintings, with or without listening to music or soundscapes, assigning metaphorical meaning to the paintings. Participants from Western countries and from Japan were able to interpret the paintings to a more limited extent. For example, they had difficulties interpreting the death painting, which they found not realistic enough. While participants from China and Japan suggested at least one interpretation, their Western counterparts explicitly stated that they had no idea what the death painting represented and what the meaning of it could be. The use of mixed media, however, helped all the participants to understand both paintings. The auditory materials had a striking effect on both the number of associations and the length of interpretations. The Chinese participants were especially notable, listing many associations and writing long texts. The Chinese and Japanese participants wrote more personal associations or memories in their questionnaires (6.5 on average for music; 10.5 for soundscapes) than did their Westerner counterparts (4 on average for music; 5 for soundscapes). The number of personal associations made and memories triggered in the control groups varied between 1 and 3 for the Chinese and Japanese participants; in contrast, no associations were made by their Western counterparts (with the exception of the one already included in the questionnaire).

With regard to color perception, the Chinese and Japanese participants did not associate "birth" with the blossoming white elder tree painting, as white is typically associated with death in Asian culture. When Asian participants listened to happy music and the spring soundscape while looking at the blossoming elder painting, they felt confused and sometimes gave a Buddhist meaning to what they saw and heard, such as reincarnation (Martinez 2013).

As a whole, the metaphorical meanings given to the paintings by the experimental groups, who listened to music and soundscapes while looking at the paintings, had a 
much broader range of themes than the ones given by the control groups, who did not suggest any themes beyond the ones already given on the questionnaire (birth and death). The experimental groups suggested themes on such universal topics such as youth, motherhood, peace, war, and love, as well as topics closely related to contemporary society, such as stress and natural disasters. The responses given by most participants reflect globalization, in the sense that sounds and paintings often were associated with popular movies, songs, and paintings from around the world (e.g., Harry Potter and Monet).

\subsubsection{Group 2: Integrating art in the language classroom}

Group 2 consisted of one control group of five students and one experimental group of five students. Both groups attended German lessons, which were based on the concept of integrated learning and teaching. Each activity was carefully structured so that it offered a clear outcome and learning goal. Even though some teachers may be skeptical regarding the use of art in the language classroom, "art definitely has a place in the language classroom as can be used in many different ways. It can be a great source for discussions as well as for practicing a variety of language forms" (Graz 2012: 87).

\subsubsection{First experiment : Procedure and result}

In the first activity, students used German to communicate, giving their opinions about a painting, and especially about the figure in the painting: a driver with a face that seems full of fear, looking behind himself (Figure 3). Apart from the driver's face in the foreground, there are a road and some trees in the background of the painting. After looking at this painting, two tranquil nature soundscapes (e.g., relaxing waves sounds, birds singing) and two aggressive urban soundscapes (e.g., screams, water boiling, knives being sharpened and heavy traffic with police sirens and honking) were used to influence the interpretations of painting. Each student listened to two soundscapes, one quiet and one aggressive, in a random order. After listening to one sound, students talked to each other about their impressions; they then listened to the next sound and exchange their ideas once again. 


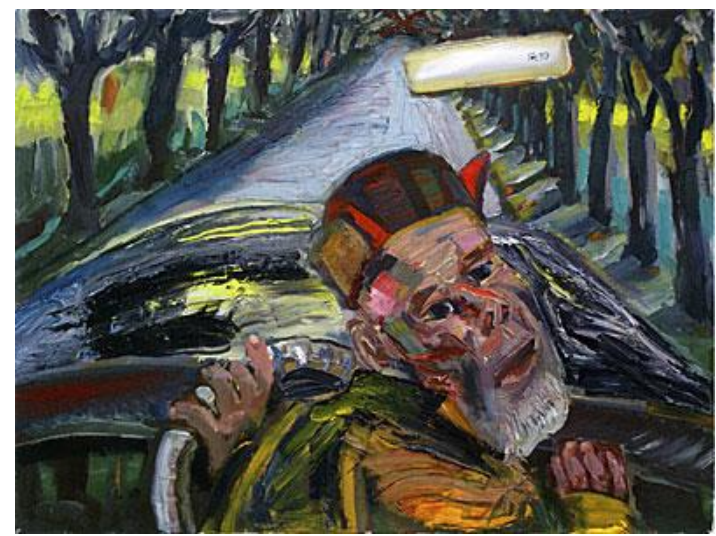

Figure 3: Selbst im Auto. Sighard Gille. 2010. Oil on canvas. 60 x $80 \mathrm{~cm}$.

The control group's impressions about the painting were generally negative: All the students felt quite irritated when the painting was shown to them, with some of them grimacing or whispering and explicitly expressing their frustration with comments such as: "What a ridiculous painting, I don't like it!" The colorful, expressive face of the driver caught their attention: After defining it as "ugly," some students argued that the painting was nonsensical and refused to give it a meaning. However, the teacher asked them to observe the painting more carefully in order to comprehend it; eventually, the students suggested that the man (probably the painter himself) must be expressing his fear of something. In addition, one student believed he must be drunk. The fact that the man is looking back behind him led another student to a more specific interpretation of this fear: The painter may be afraid of getting old, thus he looks back, trying to go back to the past, even though this is impossible.

As opposed to the control group, whose interpretation can be summarized with a single word, "fear," the experimental group expressed various opinions, with each student having a different idea about the meaning of the painting. Some students believed that the two soundscapes represented two different moments of a story. According to one student, the man first tried to escape from the police and then reached a safe place in nature; thus, for this student, the painting represents a dangerous man who managed to elude capture. Another student believed that the man, who had just left an urban area, was just starting a long business trip when he suddenly perceived the beauty of nature. He stopped, enjoying the pure sounds of nature in his ears. Looking around, he felt so attracted to the beauty of the scenery that he suddenly realized the importance of nature and of a simple life, as compared to the material life he had been leading so far. The same student concluded that the painting aims to make people think about the dangers of a life which centers around money and materiality; this student saw the painting as an appeal for nature preservation, and as a reminder that people should regularly take breaks from their busy, stressful lives in urban areas and spend time in green, quiet, relaxing places. Other students gave a new meaning to the painting after listening to the second sound, with positive meanings associated with positive sounds, and vice versa. Another interpretation argued that the two sounds represent two different sides of the man's present situation: he has to leave his family because of a war in his 
country; however, he does not feel like leaving, and he constantly remembers how nice his life in his family is, with the relaxing wave sounds symbolizing his harmonious family life. The students associated the horror sounds with hell, but explained they did not believe in hell, per se, instead arguing that these sounds symbolized a psychological problem such as the feeling of being imprisoned in one's thoughts, which can be due to the inability to make an important decision.

\subsubsection{Second experiment: Procedure and results}

In the second activity, students were tasked with inventing a life story with the help of paintings (control group) or paintings and sounds (experimental group). Each painting had to be associated with a life stage. Students presented these life stories as their own in front of the class through role-play: one person talked about his or her life, and the other person or persons reacted to what was said. The paintings represented traditional genres such as landscapes, still lifes, and portraits, as well as abstract paintings. Each student had to pick between three and four paintings; to successfully complete the exercise students needed to incorporate all the paintings, even the ones they did not find particularly inspiring, into their fictional life stories. This rule was made by the teacher in order to encourage the students to reflect on art which may at first appear boring or meaningless, necessitating the use of advanced thinking skills. This section focuses on a single painting, "Fenchel" (Figure 4) by Sighard Gille, with students' reactions showing the influence of cross-sensory coupling on its interpretation. This painting was one that students had the most difficulty integrating in their life story. As its name implies, it depicts fennel, on a dark background.

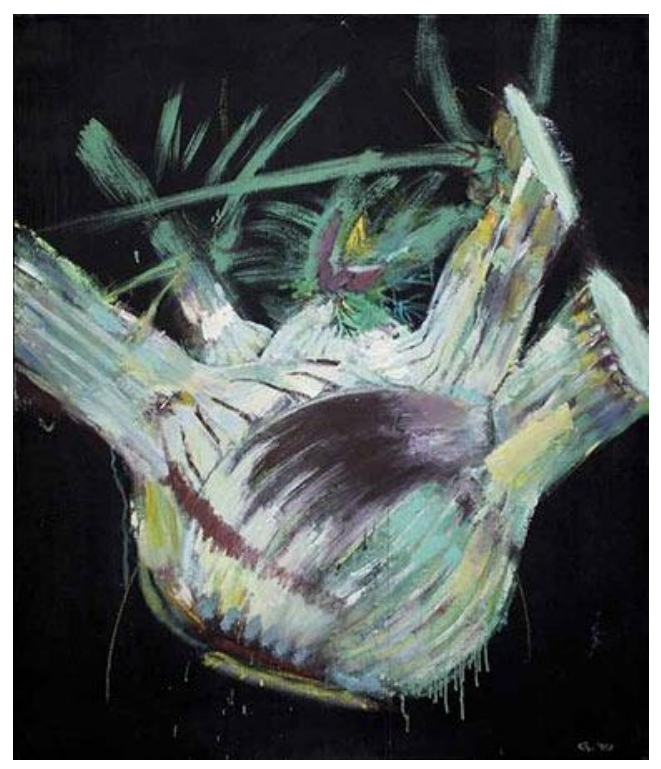

Figure 4: Fenchel. Sighard Gille. 2010. Oil on canvas.130 x $110 \mathrm{~cm}$. 
One student from the control group got confused as to the nature of the thing it represented, and even when his classmates eventually guessed that it must be some sort of plant, they did not know how to interpret such a painting. The student who chose to use it for his story eventually associated a personal memory with it. He told his role-play partners that when he was a student, he had to cook for himself, and he used onions when preparing his food.

As opposed to the control group, the experimental group listened to instrumental music from different cultures (Latin, Asian, and Western) while they were looking at the paintings. They had to freely associate at least one piece of music to each painting and to interpret the painting, justifying their choice if possible. The fennel painting was immediately picked by a student, who preferred to give it a metaphorical meaning rather than focusing on what it actually depicted. According to this student, the painting represented a trip to an unknown place and landing on an island. The Asian music was chosen by a student from a Western country who explained that this kind of music sounded very exotic to her, which definitely matched such a strange painting. When she listened to that piece of music, she immediately had the impression that she was travelling far away; she felt a great excitement and she recognized an island on the painting: the mysterious island the music took her to.

\subsubsection{Concluding remarks}

According to Graz (2012: 84), "[i]n arts-integrated classrooms, work more often clearly and meaningfully relates to students' own experiences and feelings." However, the previously discussed example shows that, without the use of soundscapes and music pieces, students did not find the painting "Selbst im Auto" ("Self in car") meaningful. Their behavior during the activity suggests that they were bored and that they completed the task without enthusiasm, as opposed to the experimental group. The use of crosssensory coupling positively affected the attitude of the students when they viewed the art, as well as their ability to verbalize messages conveyed by the painting. Crosssensory coupling helped the students during both experiments not only to give a new meaning to the painting, but also to imagine a concrete situation, and, based on this imaginary situation, to draw conclusions as to a possible meaning of the painting. Most importantly, the experimental group found the paintings meaningful in relation to their own life experiences, and were able to associate major contemporary social issues with the visual and auditory stimuli. This exercise led them to reflect on things they might not normally pay much attention to, reflecting on their own lives and the meaning of their lives.

\subsection{Facilitating intercultural communication}

The students from Group 2 who participated in art-integrated language classes were interviewed in the last stage of the experiment. They reflected on the emotional and cognitive aspects of cross-sensory coupling and the verbalization of messages conveyed 
by paintings, instrumental music, and soundscapes (Martinez, doctoral dissertation, planned on 2015/2016). Their impressions were solicited by the teacher-researcher in individual discursive interviews, which are typically used by teacher-researchers in the context of action research to discuss classroom experiments with their students (BortzDöring 2002: 314). In addition, students made spontaneous comments about the effects of cross-sensory coupling on the perception of paintings during class (which was continually videotaped).

Students stressed how easy it was to exchange ideas about the paintings after listening to sounds that, in their opinion, had a universal meaning, improving communication with students from different countries. As one student explained, "sounds such as birdsong have the same meaning for all of us, in the US, here in Europe, or even in China, when we hear such happy sounds we think of spring time; when we hear screams we get scared or at least we associate some kind of danger with them. Therefore, it was easy for us to talk about such feelings; we felt that no matter where we were from, we all perceive things in the same way" (translated from German). This quotation suggests the universality of emotions presented in Section 2.1. The human ear is capable of differentiating between many kinds of screams, expressing emotions such as joy, surprise, or fear. The context is of central importance: in the soundscape mentioned by the student, the sounds of screams were accompanied by boiling water, a mean-spirited laugh, and knives, putting to mind a frightening place. The dichotomy of hell and paradise was mentioned both by the Western and the Chinese students; the concept of hell and paradise is common knowledge - an important starting point for intercultural communication. Through their associations, the students implicitly highlighted the role of globalization. While the chosen sounds (e.g., police sirens) may differ from one continent to the other, the students have been exposed to these sounds through media such as American television shows or movies. They can then communicate on the basis on these shared emotional associations to sounds.

Emotions aroused by music, soundscapes, and paintings are thus a key tool for successful intercultural communication. Emotions play a role in the process that enables art recipients from various cultural backgrounds to comprehend and exchange ideas about pieces of art; emotional reactions lead to verbalization in the context of art perception. Art-related activities can take place in museums and also in the language classroom, where the target language used in art-integrated activities is practiced and then memorized, at least to some extent. The next chapter throws light on the positive influence of cross-sensory coupling on memory. In order to understand the results of the present study, it is important to first provide an overview of the contribution of emotions to the processes of learning and memory. 


\section{The influence of cross-sensory coupling on memory}

\subsection{Emotion, learning, and memory}

The workings of the human brain works are only partly known to neuroscientists, who, for many years, have compared this organ to a library. Studies conducted within the past decade, have shown, however, that the brain is much more complex, and more comparable to a jungle (Neuner 1998: 134-135). Pieces of information arriving at the brain are introduced into a complex network, in which the human experiencing of emotions plays a key role. As the role of emotions in learning has been better understood, moe importance has been given into the role of emotions in learning (Arnold 2002). Learning is about encoding information. Information can only be encoded if the individual feels the need to encode it; in other words, during the process of learning people are guided by their emotions, which communicate whether something has personal meaning or not, and, by extension, whether there is a reason to learn it. A major consequence of studies conducted in the field of neurobiology in the 2000s was an appeal for meaningful learning in schools (Arnold 20002, Neuner 1998). Focusing intensely on a topic may have a positive effect on learning, but it is challenging to focus on a topic one finds nonsensical. As learning means being able to remember some task previously practiced-memorization-researchers have conducted studies to determine the role of emotions in memory formation.

Memory formation involves several stages. The first stage is the encoding phase. Emotions play a role in both the first phase, encoding, and in the last phase, retrieval. In one study conducted by Hamann et al., university students were asked to look at several pictures, some of which clearly aroused positive or negative emotions, and some of which were neutral (Arnold 2002: 95-96). After four weeks, the study participants were able to best remember the pictures they associated with strong emotions. The pictures associated with positive or negative pictures were equally effective, meaning that both negative and positive emotions have an influence on memory.

\subsection{Remember Gerhard Richter in the Thunderstorm of Beethoven: Cross- sensory coupling and memory}

\subsubsection{Procedure}

The research design of the study presented in this section is based on the findings by Hamann et al. mentioned in 4. 1. Soundscapes (e.g. war sounds) and instrumental pieces (e.g. Beethoven's Sixth Symphony Thunderstorm and Spanish guitar) arousing positive and negative emotions were used with the experimental group.

During their German class, participants from the same study group as in 3.1.3 (Group 2; comprised of university students from Western countries and China) were tasked with imagining the life of a soldier named "Onkel Rudi" before he died during World War II in Normandy. The name "Onkel Rudi"-in English, "Uncle Rudy"-refers to the 
painting by the German artist Gerhard Richter, as well as to the man portrayed on it (Figure 5).

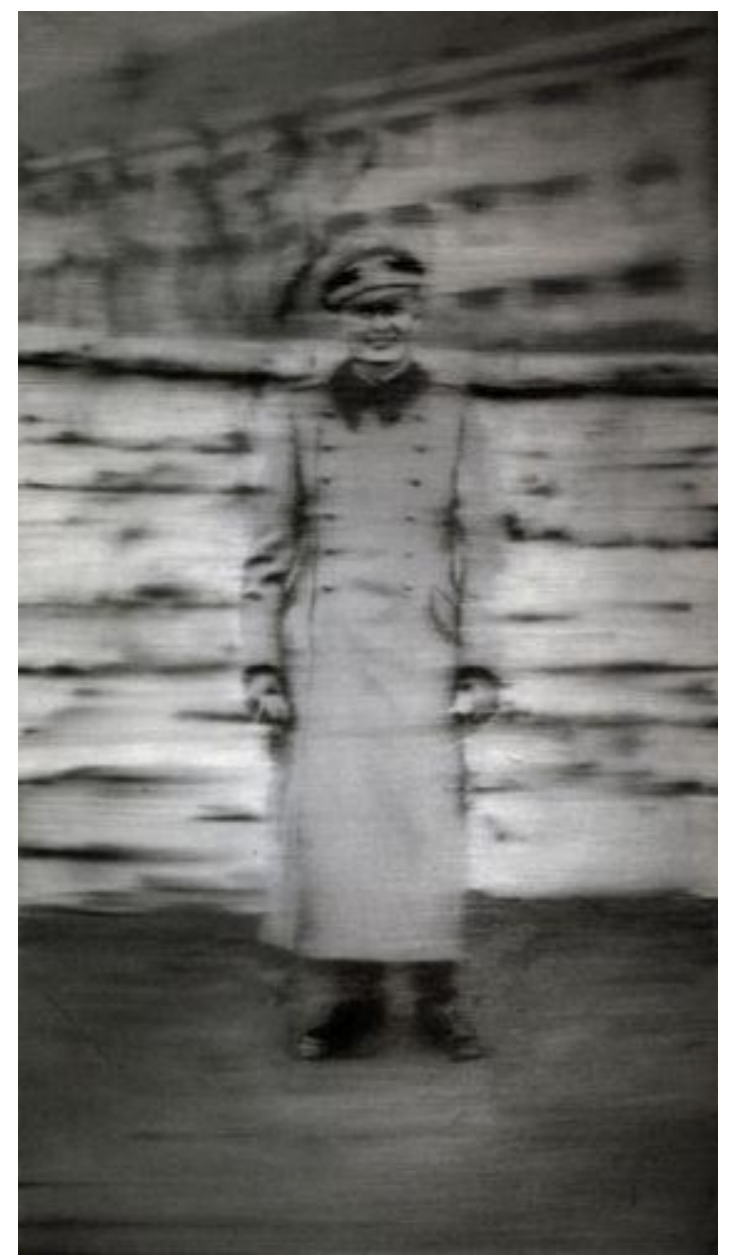

Figure 5: Onkel Rudi. Gerhard Richter. 1965. Oil on canvas. 87 x 50 cm.

The students had to associate various abstract paintings by Gerhard Richter to the stages of Uncle Rudy's life, from childhood to adulthood. Soundscapes and musical compositions had to be coupled with the paintings, as well. Thus each student had to imagine a life stage or life event, based on his or her own interpretation of visual and auditory mediums. The control group worked with the same visual mediums as the experimental group; however, there were no accompanying soundscapes or music pieces. 


\subsubsection{Results}

The students were interviewed individually by the teacher-researcher three weeks after the lesson about Onkel Rudi. The goal of the focused interview was not revealed to them, as this information might have made them nervous, which would have had negative effects both on their language skills and on the findings of the study. Instead, at the beginning of the interview they were told that they would talk about that lesson in particular, with the teacher combining elements of the focused interview and of the guided interview in order to find out what exactly students remembered, such as Uncle Rudy's story, the use of visual or auditory materials, or the meaning given to certain mediums.

The most striking difference between the experimental group and the control group was in the ability of students from the experimental group to remember not only the life stages of Uncle Rudy, but also the abstract paintings and sounds that inspired the students to imagine such life stages. No participants from the control group were able to remember that they based their story about Uncle Rudy on the interpretation of abstract paintings. When the teacher-researcher suggested this possibility, they rejected this idea, affirming that they had worked only with a single painting, Onkel Rudi. In contrast, participants from the experimental group remembered that, in addition to the portrait Onkel Rudi, they had used abstract paintings during the lesson, and that those paintings were associated with sounds. The students were, however, only partly able to remember what the paintings or sounds were actually like. Based on this evidence, although both groups were able to remember the "Onkel Rudi" lesson to some extent, the participants of the experimental group clearly were better able to remembering the different life stages, and made more precise descriptions and comments on the paintings and sounds they had observed.

\section{Conclusions}

Cross-sensoring coupling in the context of art perception involves not only the senses, but also emotions. Feeling what is seen, feeling what is heard, associating positive or negative emotions with paintings, instrumental pieces, and soundscapes: these emotional and cognitive processes enabled study participants to put emotional messages into words. The studies presented in the present paper showed that, when emotions were evoked, young-adult university students from different countries were able to exchange ideas, thus communicating successfully with their peers from other cultures. Most importantly, they realized that intercultural communication works when not only differences, but also similarities (such as those related to soundscape perception), are sought out. Associating instrumental pieces and soundscapes to contemporary paintings provoked exciting discussions about important contemporary issues; ideas that students would not have thought of otherwise suddenly became the main subject of their verbal exchanges in the art-integrated language classroom.

Art education "involves development of sensitivity to aesthetic values, and enrichment of one's personality by stimulation of his/her emotions, imagination, expression and creativity." (Krawiec 2012: 94). The studies presented in this paper show 
that the potentials of art education can be much better realized by incorporating aesthetic synesthesia, giving students the opportunity to work with mixed media, such as paintings and sounds. Pedagogic methods based on cross-sensory coupling seem to offer advantages for tasks based on interpretation and creativity. For instance, a painting which at first looks rather boring and whose potential for language use is not obvious may become exciting and offer a great potential for story-telling and interpretation when coupled with a piece of instrumental music. Motivation to verbalization thus increases, thanks to the combined use of various mediums that arouse personal memories and emotions.

A final argument in favor of the use of cross-sensory coupling is its capacity to improve recall regarding the mediums that were worked with. Even though the study presented in the fourth section of this paper cannot be representative, since it involves a very small sample, it is no surprise that, since emotions directly influence the encoding phase of information, paintings can be better remembered when more meanings and emotions are associated with them. If one sees, hears, feels, and speaks, he or she may not only enjoy the task more than if only one sense was involved, but the task will be better memorized.

\section{References}

Antweiler, Christoph (2009). Heimat Mensch. Was UNS ALLE verbindet. Hamburg: Murmann.

Arnold, Margret (2002). Aspekte einer modernen Neurodidaktik. Emotionen und Kognitionen im Lernprozess. München: Ernst Vögel.

Badstübner-Kizik, Camilla (2004)."Wortschatzarbeit, Schreiben, Hörverstehen ... und was noch? Anmerkungen zur Rolle von Kunst und Musik im Fremdsprachenunterricht". ÖDaF-Mitteilungen, 1, pp. 6-18.

Blell, Gabriele (2006). "'Seeing comes before words, and can never be quite covered by them'. Zum Verhältnis von Kunstbildern und Sprache”. In P. Drexler \& J. Klinger (Eds.). Bilderwelten. Visualisierung in Wissenschaft und Kunst. Trier: Wissenschaftlicher Verlag, pp. 3-24.

Bortz, Jürgen \& Nicola Döring (2002). Forschungsmethoden und Evaluation für Human- und Sozialwissenschaftler. Berlin: Springer Verlag.

Elger, Dietmar (2008). Gerhard Richter, Maler. Köln: DuMont.

Gabrielsson, Alf \& Patrik N. Juslin (1996). Emotional Expression in Music Performance: Between the Performer's Intention and the Listener's Experience. http://pom.sagepub. com/content/24/1/68.

Gille, Ina (2007). "Holunder". In P. Köhler (Eds.). Sighard Gille. Leipziger Schule. Malerei und Grafik. Berlin: Galerie GEGENWART, pp. 28-31.

Graz, Dominik (2012). "Learning through art. Is it worth doing?". In M. Krawiec (ed.). Od języka do kultury, literatury, sztuki i mediów. Wałbrzych: Wydawnictwo DTP Service s.c., pp. 83-88.

Haverkamp, Michael (2003). Visualisierungen auditiver Wahrnehmung - historische und neue Konzepte. Ein phänomenologischer Überblick.

http://www.michaelhaverkamp. mynetcologne.de/visualisierung_text.pdf/. 
Hays, Jeffrey (2009). Western classical music in Japan. Seiji Ozawa, Toru Takemitsu and Japanese music contest winners.

http://factsanddetails.com/japan.php?itemid=707\& catid=20\&subcatid=130.

Hays, Jeffrey (2008). Western Classical Music in China. http://factsanddetails.com/china. php?itemid=250\&catid=7\&subcatid=41.

Heibach, Christiane (2004). "Sprachkunst als synästhetisches Phänomen - Probleme und Fragestellungen”. In C. Filk et al. (Eds.). Media Synaesthetics. Konturen einer physiologischen Medienästhetik (163-179). Köln: Herbert von Halem Verlag.

Hewett, Ivan (2006). Why they are hooked on classical. http://www.telegraph.co.uk/culture/music/3652458/Why-they-are-hooked-onclassical.html.

Körner, Peter (2008). "Welchen Beitrag leistet Kunstpädagogik im Allgemeinen und Bilnerische Erziehung im Speziellen für ein gelingendes Leben?". In F. Billmayer (Eds.). Angeboten. Was die Kunstpädagogik leisten kann. München: Kopaed, pp. 119-127.

Krawiec, Marek (2012). "A virtual tour of EFL students to the world of art - theoretical and practical implications”. In: M. Krawiec (ed.). Od języka do kultury, literatury, sztuki i mediow. Wałbrzych: Wydawnictwo DTP Service s.c., pp. 89-102.

Martinez, Emilie (2013). "Listen to That Painting!: An Intercultural Experiment Based on Cross-sensory Coupling”. The International Journal of New Media, Technology, and the Arts, 7.

Neuner, Gerhard (1998). “Kognition vs. Emotion im Fremdsprachenunterricht?”. In B. Hufeisen \& B. Lindenmann (Eds.). Kognition als Schlüsselbegriff bei der Erforschung des Lehrens und Lernens fremder Sprachen. Arbeitspapiere der 18. Frühjahrskonferenz zur Erforschung des Fremdsprachenunterrichts (134-141). Tübingen: Narr.

Schafer, Raymond Murray (1988). Klang und Krach. Eine Kulturgeschichte des Hörens. Frankfurt am Main: Athenäum.

Werner, Hans-Ulrich et al. (2006). Media Soundscapes 1: Klanguage. Landschaften aus Klang und Methoden des Hörens. Siegen: Universität Siegen.

Yalin, Pan (2007). "Die Suche nach Gemeinsamkeiten als Teil der interkulturellen Kompetenz - ein wichtiges Lernziel für den Fremdsprachenunterricht". In R. Esser \& H.-J. Krumm (Eds.). Bausteine für Babylon: Sprache, Kultur, Unterricht... Festschrift zum 60. Geburtstag von Hans Barkowski (135-145). München: IUDICIUM.

\section{About the author}

Emilie Martinez is a PhD candidate at Friedrich Schiller University (FSU) in Jena, Germany. Her thesis focuses on the use of contemporary paintings, instrumental music, and soundscapes in the foreign language classroom. She also teaches German as a Foreign Language and German Literature to international students through the German as a Foreign Language Department of FSU, as well as English as a Foreign Language to German adults. 